\title{
Music and communication in music psychology
}

\author{
lan Cross \\ Centre for Music \& Science \\ Faculty of Music \\ University of Cambridge \\ http://cms.cam.ac.uk/directory/ian-cross \\ A version of a keynote paper given at \\ The Inaugural Nordoff Robbins Plus Research Conference: \\ What is music communication?, \\ London, 20 September 2013
}

To appear in Psychology of Music, 2014

\begin{abstract}
There is a general consensus that music is both universal and communicative, and musical dialogue is a key element in much musictherapeutic practice. However, the idea that music is a communicative medium has, to date, received little attention within the cognitive sciences, and the limited amount of research that addresses how and what music communicates has resulted in findings that appear to be of limited relevance to music therapy. This paper will draw on ethnomusicological evidence and an understanding of communication derived from the study of speech to sketch a framework within which to situate and understand music as communicative practice. It will outline some key features of music as an interactive participatory medium-including entrainment and floating intentionality-that can help underpin an understanding of music as communicative, and that may help guide experimental approaches in the cognitive science of music to shed light on the processes involved in musical communication and on the consequences of engagement in communication through music for interacting individuals. It will suggest that the development of such approaches may enable the cognitive sciences to provide a more comprehensive, predictive understanding of music in interaction that could be of direct benefit to music therapy.
\end{abstract}

\section{Keywords}

music therapy, communication, interaction, social uncertainty, speech 


\section{Communication in music}

The view that music is universal and communicative is widespread, not only in the field of music therapy but also in broader writing and thinking about music. As Wigram \& Elefant state (2009, p. 442), in writing of music therapy with children with ASD, "Music is a universal human form of communication that has the capacity to overcome linguistic, physical, mental and cognitive barriers to understanding with others." They further note (ibid., p. 425) that "Musical dialogue is a natural developmental outcome of the impulses for sharing communicative expression typical of normally developing children." The idea and the practice of musical dialogue is perhaps specific to music therapy, though the grounding of the utility of music as dialogue in children's developmental and communicative processes has some resonance in certain music educational practices. Music therapists have both intuitive and explicit understandings of what it is that music is communicating and how it is doing so. While these understandings are instrumental, enabling therapists both to do what they want to do with music in a therapeutic context and to establish bodies of knowledge that underpin the formation of future music therapists, there are at least two reasons for going further and trying to understand and articulate in detail just what may be meant by the idea of music as communication from scientific perspectives.

Pragmatically, in an evidence-based medical culture it is necessary to be able to defend the position that music is communicative in terms that are accessible and acceptable to other medical professionals in order to validate the position of music therapy as an evidence-based therapy. At one level this need can be accommodated by the conduct of outcome-based studies, indicating that a particular therapeutic practice such as musical dialogue is efficacious in the treatment of specific problems and disorders. Such studies can provide strong evidence for the efficacy of particular therapeutic practices, though single studies by themselves are limited in the inferences that they allow.

More compelling in the professional medical world are meta-analyses of multiple studies that can properly be compared in their designs, methods and 
findings, and several of these have been conducted in the field of music therapy. For example Gold, Wigram and Elefant (2010) analysed studies that explored the effects of music therapy on children with ASD, finding only three outcome studies that met their criteria; nevertheless, they were able to demonstrate that these three studies jointly pointed towards music therapy as having a significant effect on ASD children's verbal and gestural skills. They suggest (ibid, p. 3) that "A rationale for the use of music therapy for individuals with communication disorders is based on the findings from infancy researchers," referring to Trevarthen's (1999) account of the "...sensitivity of very young infants to the rhythmic and melodic dimensions of maternal speech, and to its emotional tone, as demonstrating that we are born ready to engage with the 'communicative musicality' of conversation." They suggest that "this premise allows music to act as an effective medium for engaging in non-verbal social exchange for children and adults with autistic spectrum disorder. Necessary communicative behaviours, such as joint attention, eye contact and turn-taking are characteristic events in shared, active music making."

Nevertheless, while outcome studies provide evidence that a therapy or therapeutic technique works, their findings are generally limited in that they tend not to address the particular properties or mechanisms that give the therapeutic techniques their efficacy. It is plausible that the effectiveness of music therapy in some contexts is to be found in the fact that it engages and provides practice in "necessary communicative behaviours" such as eye contact, etc. And on the basis of an increasing amount of experimental evidence, it is reasonable to claim that "we are born ready to engage with the communicative musicality of conversation." However, it would be helpful to be able to defend such contentions on the basis of an understanding of the specific cognitive, emotional and interpersonal processes that are involved in music-therapeutic interaction, and cognitive science should have much to offer in exploring and identifying such processes. As Wigram \& Elefant (2009, p. 423) themselves note, "To understand the power of music to heal, it should be conceived as communication that can engage human emotions and thoughts profoundly. But how can the sounds of a human voice or 
performance on a musical instrument have such an effect? This is not a question for which psychology can offer an easy answer." Wigram and Elefant really raise two questions here: first, has the psychology of music provided answers that could help explain the power of music to heal? and second, why should music therapy look to scientific psychology, or, more broadly, the cognitive sciences, for answers to such questions at all?

To address the second question, it does appears that other approaches, particularly those grounded in psychoanalytic techniques and theories, have already provided many viable answers. However, it is difficult to square psychoanalytic explanations for music therapy's efficacy with the types of explanations that are required within cognitive sciences and neuroscience (see, e.g., de L'Etoile, 2009); these latter require both explicitness, replicability and falsifiability, properties that are only clearly attainable through the application of experimental methods. This is not to argue that experimentallygrounded cognitive science should provide the "ultimate" level of explanation for the mechanisms underpinning music therapy-or indeed, for any human activity. The types of knowledge that the cognitive sciences can generate are constrained by the methods that they necessarily employ, in which a balance must be struck between experimental control and ecological validity (in effect, faithfulness to the real-life processes and situations that are being explored: see, e.g., Cole, 1996). But despite this caveat, the understandings emerging from the application of the cognitive sciences to music gain immense power by being relatable to cognitive-scientific understandings of other domains of human behaviour, providing richly ramified accounts of human behavioural, cognitive and neural processes that can allow predictive theories to be developed and tested empirically.

\section{Music as communication in the cognitive sciences}

To return to the first of the questions raised in the quote from Wigram and Elefant, scientific psychology has indeed attempted to explore and explain the effects of the sounds of human voices and instruments: and, I shall suggest, therein lies one of the problems. When the psychology of music has 
addressed music as communicative, it has generally explored music as embodying and communicating affective states or emotions or as conveying structure or as conveying motion (see, e.g., Larson, 2004; Bharucha, Curtis and Paroo, 2006; Patel et al., 2011). The idea that the experience of music is the experience of its structure has a respectable pedigree in the history of Western music theory, deriving in part from the work of Hanslick (1891/1986), and is substantiated by much experimental research (e.g., Krumhansl, 1990). The emotional powers of music are similarly well-attested by philosophers from Plato to the present day (e.g., Robinson, 2005), and again have received substantial support from experiments (see Juslin \& Sloboda, 2010). The idea of music as motion have again been focal in philosophical and phenomenological accounts of musical experience (see, e.g., Langer, 1942), and have been reinforced by experimental findings (e.g., Larson and Van Handel, 2005).

However, most of the experimental work on music that has been conducted from the perspective of the cognitive sciences has addressed music as a manifestation of patterns in sound, exploring music as heard (Cross, 2012a). A much smaller amount of research has investigated music as embodied action (see, e.g., Godøy \& Leman, 2009; Toivianen, Luck \& Thompson, 2009), but music as an interactive communicative process has received remarkably little attention. This is perhaps not surprising; music in contemporary Western societies is easily conceived of as a sonic commodity for hedonic consumption-the form in which it is most salient in those societies-rather than as an interactive process. And the overwhelming majority of the cognitive-scientific research that has been conducted on music has been carried out using Western music on Western listeners, based on the Western model of music as aural commodity. We must look beyond the Western model if we are to be able to develop ways of exploring music that can allow us to understand how it can have value as a therapeutic tool.

As ethnomusicological studies have demonstrated repeatedly over the last century, the Western model of music is only one amongst many possible notions of music, and in any case is likely to be remarkably recent (see, e.g., 
Goehr, 1989). If we are to develop cognitive-scientific understandings of the types of process that may be implicated in the communicative, dialogic, music-making that characterises much music therapy, we must look beyond the Western model for clues as to how what we might think of as music can be communicative. As Bruno Nettl (2005, p. 245) notes, "Ethnomusicologists agree that people everywhere use music to accomplish something," but the nature of that "something" is likely to vary as widely from culture to culture as is the character of each culture's music.

Nettl goes on to suggest that, notwithstanding music's diversity of use and form across cultures, it does have two common functions; (ibid, p. 253) it controls "humanity's relationship to the supernatural," and it supports "the integrity of individual social groups... by expressing the relevant central values of culture in abstracted form." In other words, for Nettl the functions of music in all societies are primarily social rather than hedonic, a view echoed time and again throughout the ethnomusicological literature where we find music manifested as a medium for active participation rather than as an aesthetic object for presentation or consumption (see, e.g., Lomax, 1968; Turino, 2008). While Nettl's suggestions firmly suggest that music has many of the attributes of a communicative medium, they do not indicate how music may fulfil these functions; indeed, many ethnomusicologists would suggest that the dynamics of particular cultures will shape and be shaped by the musics of those cultures, and that it is neither possible nor desirable to explore music's common features and properties across its many different manifestations in different societies.

However, from the perspective of the cognitive sciences, it is highly desirable-indeed, essential - to develop hypotheses about how music brings about its social effects in its different cultural manifestations, and to explore the possibility that music, across cultures, shares particular features as an interactive medium that endow it with the capacity to achieve these effects. In effect, we need an account of music as interactive process that we can operationalize: one that enables us to produce falsifiable hypotheses that we can use to understand and test the idea and actuality of music as 
communication, and to understand and test the mechanisms through which music as communication can be therapeutically effective.

To start with, we can look for functional commonalities in music across cultures: does music have common functions from the perspectives of social groups and of interacting individuals? I suggest that we can narrow down Nettl's idea of music as "supporting the integrity of individual social groups" by trying to identify the types of occasions in which music is preferentially used. When we do this, we find that music is a common feature of events such as weddings, initiation rites marking changes in social status, funerals, encounters with strangers-all are moments of potential social transformation, or situations of social uncertainty. These are situations where social outcomes-for a group, or for individuals within a group-are unclear and potentially risky, for the group or for particular individuals. I was pleased to have come up with this idea, but then found that the ethnomusicologist Norma McLeod, in discussing relationships between music and ritual in a 1974 paper, had already suggested that music is central in "the public presentation of social uncertainty" - to my chagrin, but also to my satisfaction, as I realised that this precedent gave the idea valuable support.

I would go further than McLeod and suggest that music is not only central to the public presentation of social uncertainty, it may be an optimal means of managing situations of social uncertainty (Cross, 2012b). Although we have, in the form of language, a communicative medium that seems perfectly capable of dealing with situations of social uncertainty, time and again we find that music is the preferred medium for coping with, or even organising, such situations; it is rare to find a society that does not privilege something like music (even if we might find it difficult to recognise it as music) over language in situations such as initiation, marriage or funerary rites. 


\section{Features of music as communication}

\section{Entrainment}

But how is it that music achieves this? What are the processes through which music can be deployed so as to manage situations of social uncertainty? Again, it is necessary to look for common properties of music across cultures; when we do so we find that music, in whatever forms it takes, tends to have two key properties as a mode of social interaction. As we engage in it, we jointly experience events as occurring at more-or-less regular points in time. And we experience musical events and behaviours as having meanings that are both shared and yet are intensely personal and idiosyncratic, but any tension between mutual and personal meaning is neither expressed nor shared. The first of these properties can be referred to processes of entrainment (Clayton et al, 2005), which occur when the behaviours (and attentional foci) of two or more people become periodically aligned in time. The second property I have described as "floating intentionality" (Cross, 1999); we experience music as though it exhibits intentionality or "aboutness", but precisely what music may be "about" is variable and particular to an individual-it is rarely, if ever, consensually determinate.

When people make music together, they coordinate their behaviours in time. Typically, the result is that a regular pulse structure emerges around which each participant organises their contribution to the musical event. The regular pulse structure may be continuously evident in the sounds produced, or it may be only partially evident in the temporal structure of the sounds, as in syncopations, or in complex multi-layered rhythmic structures that appear common in much of western Africa (see Arom, 1991). In either case, the regular pulse pattern appears to be phenomenally or experientially present for the participants-that is, they will time their contributions as though the regular periodic pulse is present. In effect, this regular temporal structure is experienced as shared and allows each participant to anticipate, predict and align their sound-producing behaviours to those of others; when making music together, participants entrain their attention, actions and sounds with those of other participants. This is not a unidirectional process, with participants 
entraining to a particular individual who is the time-keeper; it is likely to involve a process of continuous reciprocal adaptation of the periods and phases of the sounds and actions produced (Himberg, 2006; Konvalinka et al., 2010), with each participant continually switching between leading and following each other. An increasing amount of evidence indicates that when people entrain their behaviours with one another, they experience effects on their memory for and their attitudes towards each other (Miles, Nind \& Macrae, 2009; Miles et al., 2010); their memory for incidental attributes of each other is likely to be heightened, and they are likely to experience an enhanced sense of mutual affiliation with each other. In other words, keeping together in time, as many have noted (McNeill, 1995), has powerful effects on social bonding; music provides a medium for entrained interaction that helps sustain a sense of collective convergence.

\section{Floating intentionality}

When people engage with music through listening or performing, they are likely to experience it as meaningful: as embodying or conveying meanings that may be more or less specific. However, they are unlikely to be able to agree between themselves precisely what it is that the music means. As Swain (1996, p. 135) puts it, "...music seems full of meaning to ordinary and often extraordinary listeners, yet no community of listeners can agree among themselves with any precision that comes close to natural language about the nature of that meaning"; it is this attribute to which I refer as "floating intentionality". Nevertheless, while music's meanings are likely to be individually variable, paradoxically, they are also likely to be experienced as immediate and direct; while a participant may experience the music as embodying a meaning that is wholly personal to them, it may also seem to be an intrinsic attribute of the music-the music "means like it sounds." We can interpret this immediacy as arising from a tendency to experience the acoustical signals entailed by the music as though there were a necessary causal connection between the signals' structure and the affective and motivational states of their producers (see Cross, 2008; 2009). 
This paradox - that music appears to embody unmediated, direct meaning, but what any particular instance of music may mean seems different in the experience of different individuals - can be dealt with by the realisation that, unlike in speech, the meanings elicited by music are not required to be made mutually explicit by individuals interacting in music (Cross, 2012b). Each interacting individual can thus interpret musical meanings more-or-less entirely idiosyncratically without necessarily coming into conflict with the interpretations of others. Hence music can be thought of as an optimal medium for managing situations of social uncertainty, by enhancing a sense of mutual affiliation between participants and by allowing them to experience the significance of a joint event as both deeply personal yet shared. Situations of social uncertainty may range in scope from societal (a recent local example might be the London Olympics_think of the role of music in the opening ceremony!) to dyadic, as in a caregiver-infant interaction (which, as Trevarthen and others have noted, is likely to exhibit highly musical characteristics)—or, of course, a music-therapeutic encounter.

\section{Music and speech as communicative media}

Interaction in music seems quite unlike interaction in language, although both can be described as "communicative." Interaction through the medium of language-speech-is usually conceptualised as a process of information exchange, which requires that participants establish a collective consensus as to the informational content of the interaction; interlocutors must establish common ground-"mutual knowledge, mutual beliefs, and mutual assumptions" that allows participants in a communicative linguistic interaction "to coordinate on content" (Clark \& Brennan, 1991). This allows interlocutors to make use of language's capacity for unambiguous reference in engaging in communicative transactions concerning states of affairs in the world.

Music cannot communicate information about states of affairs in the world. But interactive engagement with others through music provides the space for the sense to emerge that the attitudes and motivations of each interactant are being honestly communicated to each other and are in alignment. In fact, 
interaction in language also relies implicitly on such a sense, but in most analyses of interaction in speech this phatic or relational dimension of communication has been overlooked in favour of its transactional dimension; it is, however, critical in enabling communication in speech, in establishing and maintaining the channels for the exchange of information (see Coupland, Coupland \& Robinson, 1992). This relational dimension of communication, allowing interactants to align their attitudes and motivations with each other, is what is foregrounded in musical interaction ${ }^{1}$.

This perspective on music as communicative interaction suggests that music and language should not be viewed as separable domains of human behaviour. Language_or more properly, language in action, speechprivileges the transactional dimension of communication, enabling interactants to exchange information and coordinate goal-directed behaviour. But speech relies on the relational dimension to establish and maintain the social relations between interactants that frame the exchange of information and the coordination of action. Music privileges the relational dimension to the apparent exclusion of the transactional, though many types of musical usages can be interpreted as partly transactional (such as the use of music to coordinate group actions, as in work-songs, or in the articulation of group identity in the singing of football fans). Together, speech and music can be conceived of as primary components of the human communicative toolkit, each optimised for different ends.

This perspective on music and speech is supported by an increasing amount of experimental evidence, which indicates that common cognitive and neural processes are implicated in the perception and production of aspects of both music and speech. A large literature now endorses the idea that speech and music are indissociable in early infancy (for an overview see Brandt, Gebrian \& Slevc, 2012); musical expertise has been shown to be advantageous for aspects of second-language learning (see, e.g., Milovanov et al., 2008); similar mechanisms appear to underlie emotional inferences from both vocalizations and music (Escoffier et al, 2012); syntax in language and music appear to be processed largely by means of the same brain circuitry (Koelsch, 
2012); there is substantial overlap in brain regions involved in processing speech and song (Schön et al., 2010); and speakers of tone languages appear to have some advantages in the cognitive and neural processing of music over speakers of non-tonelanguages (Bidelman, Hutka \& Moreno, 2013) that have been interpreted as suggesting formative influences for culture on what might have been thought to be "universal" mental processes (Wong et al, 2012).

If music and language are so intertwined, one might ask why we appear to need both. After all, language can also be used to fulfil what I have suggested is the primary function of music, the management of situations of social uncertainty, so music could be viewed as unnecessary. However, language, because of its capacity to be unambiguously referential, can never be quite as effective as can music in leading interactants' affective and motivational states into alignment. Moreover, music has the advantage over language of being able to integrate the simultaneous experience of multiple participants into a collective communicative interaction. But rather than thinking of speech and music as two distinct subcomponents of the human communicative toolkit, it is better to construe them as overlapping categories of interactive behaviour; most "everyday" speech interaction is more than a little musical in the ways in which it serves social ends, while most "musical" interactions-particularly in traditional societies-are embedded in specific social processes that direct joint action towards particular goals (see Cross, 2012b).

\section{Future directions}

The framework sketched out here provides a fairly well-grounded basis for the exploration of music as an interactive, communicative medium, but we are at the beginning of a long and difficult research process. Virtually all research in the cognitive sciences and in neuroscience-even in respect of speech and music-has concentrated on individual perceptions, cognitions and behaviours. Only recently has a focus on exploring the behavioural, cognitive and neural processes involved in social interaction begun to emerge, identifying phenomena such as action simulation and mental state attribution 
(Sebanz \& Knoblich, 2009), postural and gaze coordination (Shockley, Richardson \& Dale, 2009), action prediction (Vesper et al., 2011), imitation and entrainment (Garrod \& Pickering, 2009) as key elements in alignment in social interaction. Neuroscience is beginning to address the issue of interaction (Hari \& Kujala, 2009; Hasson et al., 2011), and has already indicated that common patterns of brain activity are evident when two people coordinate their behaviours (e.g., Dumas et al, 2010). Interestingly, some of the earliest studies to demonstrate coordination of brain activity across interacting individuals explored musical interaction (Lindenberger et al., 2009), and recent work has shown that even joint music listening can activate similar brain networks across individuals and that these networks share a common time-course of activation (Abrams et al., 2013).

Nevertheless, most of what requires to be known remains unknown. Neither the processes involved in communicative musical interaction (at the cognitive, neural and behavioural levels), nor the consequence of repeated engagement in such processes, are well-understood. Preliminary results from work in progress at Cambridge (the Joining-in project: see Hawkins, Cross \& Ogden, 2013) on interaction in spontaneous speech and in music suggest that both domains are underpinned by common temporal processes. Other recent research indicates that there are significant consequences of repeated engagement in participatory music for both school-age children (Rabinowitch et al., 2013) and infants (Gerry, Unrau \& Trainor, 2012) on the capacity for social behaviour. However, such studies are still rare and results remain indicative rather than definitive. Nevertheless, research into the processes and effects of interactive music now has the support of a substantial and expanding literature that addresses general processes of human interaction, and musical interaction is increasingly being recognised as a significant domain of human behaviour that requires exploration.

The issue of how this approach to understanding music as communication might be explored and applied in music therapy remains to be addressed. As noted above, there is as yet a paucity of research on non-clinical populations, but as the field develops, more clear leads are likely to emerge. Of course, 
even when non-clinical research is rooted in naturalistic contexts (such as those explored in the Joining-in project) much work will be required to refine the implications of experimental findings so as to render them relevant to clinical contexts. For example, most work on musical interaction has explored symmetrical dyadic processes (where both participants have equal and interchangeable roles), not because that is the "natural" framework within which to understand and explain music as communicative, but because symmetrical dyadic contexts offer a laboratory within which we can begin to test hypotheses about how musical interaction works. In a symmetrical dyadic context, the number of possible parameters and variables that we may wish either to control (so as to exclude them from consideration within the experimental context) or to manipulate (as independent variables in the experiment) are more manageable than in asymmetrical or ensemble contexts, where the number of potential variables is likely to be combinatorially explosive and unmanageable; yet at some point experimental research will have to explore interactions in asymmetrical dyads and in ensembles. Despite these caveats, the emergence of interaction as a key theme in cognitive, behavioural and neuroscientific research should have significant benefits for the development of music therapy. As the research focus within the cognitive sciences on social interaction intensifies, understanding the dynamics of communicative and dialogic music therapy is likely to become an increasingly mainstream research question. 


\section{References}

Abrams, D. A., Ryali, S., Chen, T., Chordia, P., Khouzam, A., Levitin, D. J., Menon, V. (2013). Inter-subject synchronization of brain responses during natural music listening. European Journal of Neuroscience, 37(9), 1458-1469.

Arom, S. (1991). African polyphony and polyrhythm: Musical structure and methodology. Cambridge: Cambridge University Press.

Bharucha, J. J., Curtis, M., \& Paroo, K. (2006). Varieties of musical experience. Cognition, 100(1), 131-172.

Bidelman, G. M., Hutka, S., \& Moreno, S. (2013). Tone Language Speakers and Musicians Share Enhanced Perceptual and Cognitive Abilities for Musical Pitch: Evidence for Bidirectionality between the Domains of Language and Music. PLOS ONE, 8(4), e60676.

Brandt, A., Gebrian, M., \& Slevc, L. R. (2012). Music and early language acquisition. Frontiers in Psychology, [doi: 10.3389/fpsyg.2012.00327](1664-1078 (Electronic)).

Bruner, J. (1986). Actual minds, possible worlds. London: Harvard University Press.

Clark, H. H., \& Brennan, S. E. (1991). Grounding in communication. In L. B. Resnick, J. M. Levine \& S. D. Teasley (Eds.), Perspectives on socially shared cognition (pp. 127-149). Washington, DC, US: American Psychological Association.

Clayton, M., Sager, R., \& Will, U. (2005). In time with the music: The concept of entrainment and its significance for ethnomusicology. ESEM counterpoint, 1, $1-45$.

Cole, M. (1996). Cultural Psychology. London: Belknap Press of Harvard University Press.

Coupland, J., Coupland, N., \& Robinson, J. D. (1992). "How Are You?": Negotiating Phatic Communion. Language in Society, 21(2), 207-230.

Cross, I. (1999). Is music the most important thing we ever did? Music, development and evolution. In S. W. Yi (Ed.), Music, mind and science (pp. 10-39). Seoul: Seoul National University Press.

Cross, I. (2008). Musicality and the human capacity for culture. Musicae Scientiae, Special Issue, 127-143.

Cross, I. (2009). The evolutionary nature of musical meaning. Musicae Scientiae, Special Issue: Music and Evolution, 147-167.

Cross, I. (2012a). Cognitive Science and the Cultural Nature of Music. Topics in Cognitive Science, 4(4), 668-677.

Cross, I. (2012b). Music as a social and cognitive process. In P. Rebuschat, M. Rorhrmeier, J. A. Hawkins \& I. Cross (Eds.), Language and music as cognitive systems (pp. 313-328). Oxford: Oxford University Press.

de L'Etoile, S. (2009). Processes of music therapy: Clinical and scientific rationales and models. In S. Hallam, I. Cross \& M. Thaut (Eds.), Oxford Handbook of Music Psychology (pp. 493-502). Oxford: Oxford University Press.

Dumas, G., Nadel, J., Soussignan, R., Martinerie, J., \& Garnero, L. (2010). InterBrain Synchronization during Social Interaction. PLOS ONE, 5(8), e12166.

Escoffier, N., Zhong, J., Schirmer, A., \& Qiu, A. (2012). Emotional expressions in voice and music: Same code, same effect? Human Brain Mapping, 34(8), 1796-1810

Garrod, S., \& Pickering, M. J. (2009). Joint Action, Interactive Alignment, and Dialog. Topics in Cognitive Science, 1(2), 292-304.

Gerry, D., Unrau, A., \& Trainor, L. J. (2012). Active music classes in infancy enhance musical, communicative and social development. Developmental Science, 
15(3), 398-407.

Godøy, R. I., \& Leman, M. (Eds.). (2009). Musical gestures: sound, movement, and meaning. London: Routledge.

Goehr, L. (1989). Being True to the Work. The Journal of Aesthetics and Art Criticism, 47(1), 55-67.

Gold C, Wigram T, Elefant C. (2010) Music therapy for autistic spectrum disorder. Cochrane Database of Systematic Reviews 2006, Issue 2. Art. No.: CD004381. DOI: 10.1002/14651858.CD004381.pub2

Hanslick, E. (1891/1986). On the musically beautiful: a contribution towards the revision of the aesthetics of music (G. Payzant, Trans.). New York: Hackett Publishing Co.

Hari, R., \& Kujala, M. V. (2009). Brain Basis of Human Social Interaction: From Concepts to Brain Imaging. Physiological Reviews, 89(2), 453-479.

Hasson, U., Ghazanfar, A. A., Galantucci, B., Garrod, S., \& Keysers, C. (2011). Brain-to-brain coupling: a mechanism for creating and sharing a social world. Trends in Cognitive Sciences, 16(2), 114-121.

Hawkins, S., Cross, I., \& Ogden, R. (2013). Communicative interaction in spontaneous music and speech. In M. Orwin, C. Howes \& R. Kempson (Eds.), Music, language and interaction (pp285-329), London: College Publications.

Himberg, T. (2006). Co-operative Tapping and Collective Time-keeping - differences of timing accuracy in duet performance with human or computer partner. In M. Baroni, A. R. Addessi, R. Caterina \& M. Costa (Eds.), Proceedings of the 9th International Conference on Music Perception \& Cognition (pp. 377). Bologna, Italy: August, 2006 ICMPC.

Juslin, P., \& Sloboda, J. A. (Eds.). (2010). Oxford handbook of music and emotion. Oxford: Oxford University Press.

Koelsch, S. (2012). Brain \& music. Oxford: Wiley-Blackwell.

Konvalinka, I., Vuust, P., Roepstorff, A., \& Frith, C. D. (2010). Follow you, follow me: Continuous mutual prediction and adaptation in joint tapping. The Quarterly Journal of Experimental Psychology, 63(11), 2220 - 2230.

Krumhansl, C., L. (1990). Cognitive foundations of musical pitch. New York ; Oxford: Oxford University Press.

Langer, S. (1942). Philosophy in a new key. Cambridge, M.A.: Harvard University Press.

Larson, S., \& VanHandel, L. (2005). Measuring musical forces. Music Perception, 23(2), 119-136.

Larson, S. (2004). Musical forces and melodic expectations: Comparing computer models and experimental results. Music Perception, 21(4), 457-498.

Lindenberger, U., Li, S.-C., Gruber, W., \& Muller, V. (2009). Brains swinging in concert: cortical phase synchronization while playing guitar. $B M C$ Neuroscience, 10(1), 1-22.

Lomax, A. (1968). Folk song style and culture. Washington DC: American Association for the Advancement of Science.

McLeod, N. (1974). Ethnomusicological Research and Anthropology. Annual Review of Anthropology, 3, 99-115.

McNeill, W. (1995). Keeping together in time: dance and drill in human history. Cambridge, MA: Harvard University Press.

Miles, L. K., Nind, L. K., Henderson, Z., \& Macrae, C. N. (2010). Moving memories: Behavioral synchrony and memory for self and others. Journal of Experimental Social Psychology, 46(2), 457-460. 
Miles, L. K., Nind, L. K., \& Macrae, C. N. (2009). The rhythm of rapport: Interpersonal synchrony and social perception. Journal of Experimental Social Psychology, 45(3), 585-589.

Milovanov, R., Huotilainen, M., Välimäki, V., Esquef, P. A. A., \& Tervaniemi, M. (2008). Musical aptitude and second language pronunciation skills in schoolaged children: Neural and behavioral evidence. Brain Research, 1194(0), 8189.

Nettl, B. (2005). The study of ethnomusicology: thirty-one issues and concepts (2nd ed.). Urbana \& Chicago: University of Illinois Press.

Patel, S., Scherer, K. R., Björkner, E., \& Sundberg, J. (2011). Mapping emotions into acoustic space: The role of voice production. Biological Psychology, 87(1), 93-98.

Rabinowitch, T.-C., Cross, I., \& Burnard, P. (2013). Long-term musical group interaction has a positive influence on empathy in children. Psychology of Music, 41(4), 484-498.

Robinson, J. (2005). Deeper than reason: emotion and its roles in literature, music and the arts. Oxford: Oxford University Press.

Schön, D., Gordon, R., Campagne, A., Magne, C., Astésano, C., Anton, J.-L., Besson, M. (2010). Similar cerebral networks in language, music and song perception. Neurolmage, 51(1), 450-461.

Sebanz, N., \& Knoblich, G. (2009). Prediction in Joint Action: What, When, and Where. Topics in Cognitive Science, 1(2), 353-367.

Shockley, K., Richardson, D. C., \& Dale, R. (2009). Conversation and Coordinative Structures. Topics in Cognitive Science, 1(2), 305-319.

Swain, J. P. (1996). The Range of Musical Semantics. The Journal of Aesthetics and Art Criticism, 54(2), 135-152.

Toiviainen, P., Luck, G., \& Thompson, M. R. (2009). Embodied Meter: Hierarchical Eigenmodes in Music-Induced Movement. Music Perception, 28(1), 59-70.

Trevarthen, C. (1999). Musicality and the intrinsic motive pulse: Evidence from human psychobiology and infant communication. Musicae Scientiae, special issue: Rhythm, musical narrative, and the origins of human communcation, 155-215.

Turino, T. (2008). Music as social life: the politics of participation. London: University of Chicago Press.

Vesper, C., van der Wel, R., Knoblich, G., \& Sebanz, N. (2011). Making oneself predictable: reduced temporal variability facilitates joint action coordination. Experimental Brain Research, 211(3), 517-530.

Wigram, T., \& Elefant, C. (2009). Therapeutic dialogues in music: Nurturing musicality of communication in children with autistic spectrum disorder and Rett syndrome. In S. Malloch \& C. Trevarthen (Eds.), Communicative musicality: exploring the basis of human companionship (pp. 423-445). Oxford: Oxford University Press.

Wong, P. C. M., Ciocca, V., Chan, A. H. D., Ha, L. Y. Y., Tan, L.-H., \& Peretz, I. (2012). Effects of Culture on Musical Pitch Perception. PLOS ONE, 7(4), e33424. 
${ }^{1}$ In participatory, unscripted, music-making, music is effectively appearing to act as an honest signal, unambiguously and reciprocally revealing the attitudes and motivations of each participant to each other and allowing them to become aligned. In listening to music-and perhaps in the ensemble performance of scripted presentational music (to use Turino's 2008 term) - this aspect of music is likely to be inferred by a listener (or performer) on the basis of the signals embodied in the music; the situation lacks reciprocity and the "honesty" of the musical signal can be thought of as virtual rather than actual, the music's relational dimension being "subjunctivized," in a manner similar to the experience of the narrative worlds that are presented in literature or in drama (cf. Bruner, 1986: 26). 